\title{
Preparation and Properties of Crystalline IGZO Thin Films
}

\author{
Xiao Wang ${ }^{1, *}$, Zhihua Shen ${ }^{2}$, Jie $\mathrm{Li}^{3}$ and Shengli $\mathrm{Wu}^{3, *}$ \\ 1 School of Electronic Information and Artificial Intelligence, Shaanxi University of Science and Technology, \\ Xi'an 710049, China \\ 2 School of Electronics and Information Engineering, Nantong Vocational University, Nantong 226007, China; \\ 9000082@mail.ntvu.edu.cn \\ 3 Key Laboratory for Physical Electronics and Devices of the Ministry of Education, School of Electronic Science \\ and Engineering, Xi'an Jiaotong University, Xi'an 710049, China; jie_li@mail.xjtu.edu.cn \\ * Correspondence: wangxiao@sust.edu.cn (X.W.); slwu@mail.xjtu.edu.cn (S.W.)
}

Citation: Wang, X.; Shen, Z.; Li, J.; $\mathrm{Wu}, \mathrm{S}$. Preparation and Properties of Crystalline IGZO Thin Films. Membranes 2021, 11, 134. https:// doi.org/10.3390/membranes11020134

Academic Editors: $\mathrm{He} \mathrm{Li}$ and Yifei Wang

Received: 27 January 2021

Accepted: 11 February 2021

Published: 14 February 2021

Publisher's Note: MDPI stays neutral with regard to jurisdictional claims in published maps and institutional affiliations.

Copyright: (C) 2021 by the authors. Licensee MDPI, Basel, Switzerland. This article is an open access article distributed under the terms and conditions of the Creative Commons Attribution (CC BY) license (https:/ / creativecommons.org/licenses/by/ $4.0 /)$.

\begin{abstract}
IGZO thin films can be used as active layers of thin-film transistors and have been widely studied. However, amorphous indium gallium zinc oxide (IGZO) fabricated at room temperature is vulnerable in subsequent manufacturing processes, such as etching and sputtering; this limits IGZO thin film transistors' (TFTs) use in commercial products. In this paper, we prepared a c-axis crystallized IGZO thin film by Radio Frequency (RF) sputtering at $180^{\circ} \mathrm{C}$, with a $50 \% \mathrm{O}_{2}$ ratio and $110 \mathrm{~W}$ power. XRD images show that the crystallized film has an obvious diffraction peak near $31^{\circ}$, and the spacing between the crystal surfaces was calculated to be $\approx 0.29 \mathrm{~nm}$. The HRTEM map confirmed the above results. The stability of IGZO thin films was investigated by etching them with an acid solution. The crystalline IGZO films exhibited better acid corrosion resistance, and their anticorrosion performance was $74 \%$ higher than that of amorphous IGZO (a-IGZO) films, indicating the crystalline IGZO film can provide more stable performance in applications.
\end{abstract}

Keywords: indium gallium zinc oxide (IGZO) thin film; RF sputtering; c-axis aligned crystal IGZO; corrosion resistance

\section{Introduction}

For their particular properties, transparent-oxide thin films can be used widely in thin film transistors (TFTs) as control units in liquid crystal displays (LCDs), flexible activematrix organic light-emitting diode (AM-OLED) displays, wearable devices, photoelectric devices, thermoelectric generators and chemical and biological sensors [1-7]. Among many transparent-oxide thin film semiconductor materials, the indium gallium zinc oxide (IGZO) membrane is considered the most promising active layer substitution for the traditional hydrogenated amorphous silicon (a-Si)-based TFT and the low temperature poly-silicon (LTPS)-based TFT used in the backplanes of LCD and AM-OLED displays.

IGZO TFTs have the advantages of high mobility, a reasonable on/off ratio, high optical transparency in the visible region and a large area of deposition at low temperatures $[8,9]$. Although high-definition displays and foldable displays using IGZO TFTs have been made $[10,11]$, the property stability and mass production techniques are still the main obstacles to IGZO TFTs replacing Si-based TFTs commercially. Meanwhile, in the development of large, high frequency, high resolution and low power flat panel displays for the next generation, the signal delay and aperture ratio of the gate lines and data lines are main constraints. Therefore, back-channel etched (BCE) structural TFTs are widely used for their simpler structure and fewer processes, which reduce the production costs while allowing a shorter channel length and smaller parasitic capacitance. The signal distortion could be decreased by using the BCE structure. However, the amorphous IGZO (a-IGZO) fabricated at room temperature is easily damaged by subsequent fabrication process, such as etching and sputtering, restricting the applications of IGZO TFTs in commercial products. Specifically, in commercial production and manufacturing, problems caused by damage 
of the back channel of IGZO TFTs are inevitable, and improvement of the dependability and elimination of the undulations in characteristics are difficult, and it seems that the achievement of massive use of IGZO TFTs could take a long time [12].

In order to solve the performance stability problem caused by a-IGZO in the manufacturing process, Yamazaki et al. formed a partially nanocrystalline state IGZO film in which the c-axis of the crystal is aligned, and this structure has been referred to as c-axis aligned crystal (CAAC) IGZO [13]. Devices fabricated with CAAC IGZO film exhibit similar uniformity to a-IGZO devices while improving stability and exhibiting extremely low leakage currents. Park et al. formed CAAC IGZO at above $800{ }^{\circ} \mathrm{C}$ for annealing and investigated the effect of crystalline IGZO thin films on device performance, and evaluated the device reliability of CAAC IGZO under positive/negative bias stress with/without illumination. Remarkable improvement of the device reliability for CAAC IGZO TFTs was observed, especially under the bias stress with illumination, and they believed that this came from lower defect density compared with the a-IGZO film [14]. Hiramatsu et al. proposed that the high crystallinity of CAAC IGZO is important for the inhibition of oxygen vacancies, which play an important role in the characteristics of IGZO-based devices [15]. These features allow CAAC IGZO to be used as an ideal candidate for applications in traditional displays, and it is potentially useful for various other products, such as low-power displays, non-volatile memory devices, novel sensors and large-scale integrations [16,17].

In this paper, under the premise of changing the preparation parameters of a-IGZO as little as possible, the effects of RF sputtering parameters, such as $\mathrm{Ar} / \mathrm{O}_{2}$ ratio, power and temperature on the preparation of crystal IGZO thin films is discussed in detail by using the design and analysis of experiment (DOE) method. Film deposition under optimized conditions shows a high degree of crystallinity and strong c-axis alignment. Highly oriented films were obtained directly by RF sputtering at an elevated substrate temperature of $180^{\circ} \mathrm{C}$ with $50 \% \mathrm{O}_{2}$ fractions. The structure of the prepared IGZO film was characterized by $\mathrm{X}$-ray diffraction (XRD) and high-resolution transmission electron microscopy (HRTEM) imaging. The corrosion resistance of IGZO films under different preparation conditions was also characterized by the etching rate.

\section{Materials and Methods}

The alkaline-free glass substrate was gradually cleaned with acetone, alcohol and deionized water in the ultrasonic cleaning machine and used as a coating substrate directly. The IGZO film was fabricated by RF magnetron sputtering (ACS-4000-C4 magnetron sputtering instrument: ULVAC Company, Chigasaki, Japan) with different parameters followed by annealing at $400{ }^{\circ} \mathrm{C}$. The atomic composition ratio of the sputter target was: $\mathrm{Ga}: \mathrm{Zn}: \mathrm{O}=1: 1: 1: 4$. According to the preliminary investigation, the temperature, $\mathrm{Ar} / \mathrm{O}_{2}$ ratio and RF power were selected as the main factors affecting the crystallization of IGZO thin films. Based on the technical specifications of the machine available, the levels were as follows: temperature from 100 to $180^{\circ} \mathrm{C}$, and it remained unchanged during preparation, $\mathrm{Ar} / \mathrm{O}_{2}$ ratio from 30:30 to 30:3, power from 80 to $140 \mathrm{~W}$. See Table 1.

Table 1. Factors and levels used in RF sputtering.

\begin{tabular}{cccc}
\hline Factors & Level 1 & Level 2 & Level 3 \\
\hline Temperature $\left({ }^{\circ} \mathbf{C}\right)$ & 100 & 140 & 180 \\
Ar/ $\mathbf{O}_{\mathbf{2}}(\mathbf{s c c m} / \mathbf{s c c m})$ & $30: 3$ & $30: 15$ & $30: 30$ \\
Power $(\mathbf{W})$ & 80 & 110 & 140 \\
\hline
\end{tabular}

In order to obtain the relationship between sputtering parameters and film properties as well as possible, nine experiments with three factors and three levels were carried out by DOE method. The detailed preparation parameters were as in Table 2. More specifically, in terms of temperature factor, level 1 was $100^{\circ} \mathrm{C}$; level 2 was $140{ }^{\circ} \mathrm{C}$; level 3 was $180^{\circ} \mathrm{C}$. Similarly, in the case of the $\mathrm{Ar} / \mathrm{O}_{2}$ ratio, level 1 was 30:3; level 2 was 30:15; level 3 was 30:30. For sputtering power, level 1 was $80 \mathrm{~W}$; level 2 was $110 \mathrm{~W}$; level 3 was $140 \mathrm{~W}$. In the 
subsequent paragraphs, we have abbreviated conditions $1-9$ as $\mathrm{C} 1-\mathrm{C} 9$, and the samples prepared from those conditional parameters were recorded as S1-1, S2-1 and so on.

Table 2. Orthogonal table of RF sputtering parameters.

\begin{tabular}{cccc}
\hline Condition & Temperature $\left({ }^{\circ} \mathbf{C}\right)$ & Ar/ $\mathbf{O}_{\mathbf{2}}(\mathbf{s c c m})$ & Power $(\mathbf{W})$ \\
\hline $\mathbf{1}$ & 100 & $30: 3$ & 80 \\
$\mathbf{2}$ & 100 & $30: 15$ & 110 \\
$\mathbf{3}$ & 100 & $30: 30$ & 140 \\
$\mathbf{4}$ & 140 & $30: 3$ & 110 \\
$\mathbf{5}$ & 140 & $30: 15$ & 140 \\
$\mathbf{6}$ & 140 & $30: 30$ & 80 \\
$\mathbf{7}$ & 180 & $30: 3$ & 140 \\
$\mathbf{8}$ & 180 & $30: 15$ & 80 \\
$\mathbf{9}$ & 180 & $30: 30$ & 110 \\
\hline
\end{tabular}

After the film was prepared, the thickness of the membrane was measured by ellipsometer, and the influences of parameters on the deposition rate (D.R.) were investigated. The structure of prepared IGZO film was characterized by XRD (Rigaku company, Osaka, Japan) and HRTEM imaging (FEI company, Portland, OR, USA). The corrosion resistance of IGZO films under different preparation conditions was characterized by the etching rate.

\section{Results and Discussion}

\subsection{The Effects of Sputtering Parameters on the Deposition Rate}

In order to maintain the same thickness for subsequent XRD and HRTEM tests, we first measured the film deposition rates of different conditions. The deposition rate was obtained by the ratio of thickness to time of the thin film deposited on the glass substrate, under different parameters, and the thickness was determined by ellipsometer. Using the conditions shown in Table 1, after sputtering for $5 \mathrm{~min}$, the thicknesses of IGZO films and the deposition rate under different conditions were obtained as shown in Table 3. Next, see the corresponding experiment result analysis in Table 4 and Figure 1.

Table 3. Orthogonal table of IGZO film deposition rate.

\begin{tabular}{cccccc}
\hline Condition & $\begin{array}{c}\text { Temp. } \\
\left({ }^{\circ} \mathbf{C}\right)\end{array}$ & $\begin{array}{c}\text { Ar/O } \\
(\mathbf{s c c m})\end{array}$ & $\begin{array}{c}\text { Power } \\
(\mathbf{W})\end{array}$ & $\begin{array}{c}\text { THK. } \\
(\mathbf{n m})\end{array}$ & $\begin{array}{c}\text { D.R. } \\
(\mathbf{n m} / \mathbf{m i n})\end{array}$ \\
\hline $\mathbf{1}$ & 100 & $30: 3$ & 80 & 129 & 25.8 \\
$\mathbf{2}$ & 100 & $30: 15$ & 110 & 111 & 22.2 \\
$\mathbf{3}$ & 100 & $30: 30$ & 140 & 126 & 25.2 \\
$\mathbf{4}$ & 140 & $30: 3$ & 110 & 180 & 36 \\
$\mathbf{5}$ & 140 & $30: 15$ & 140 & 141 & 28.2 \\
$\mathbf{6}$ & 140 & $30: 30$ & 80 & 72 & 14.4 \\
$\mathbf{7}$ & 180 & $30: 3$ & 140 & 234 & 46.8 \\
$\mathbf{8}$ & 180 & $30: 15$ & 80 & 78 & 15.6 \\
$\mathbf{9}$ & 180 & $30: 30$ & 110 & 96 & 19.2 \\
\hline
\end{tabular}

Table 4. Range analysis table of IGZO film deposition rate.

\begin{tabular}{cccc}
\hline Averge data of D.R. & Temperature & Ar/ $\mathbf{O}_{\mathbf{2}}$ & Power \\
\hline Level 1 & 24.4 & 36.2 & 18.6 \\
Level 2 & 26.2 & 22 & 25.8 \\
Level 3 & 27.2 & 19.6 & 33.4 \\
Range & 2.8 & 16.6 & 14.8 \\
\hline
\end{tabular}




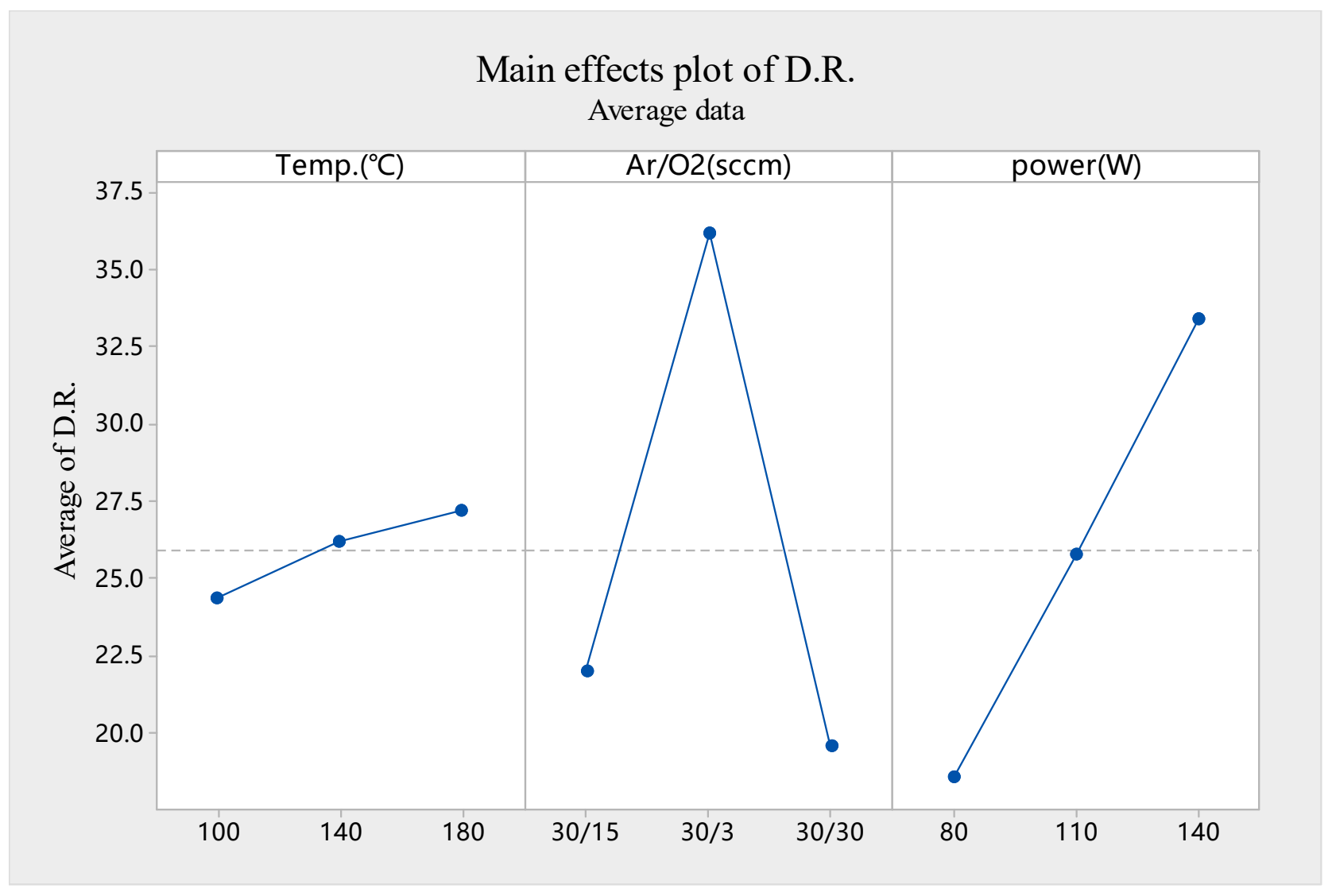

Figure 1. A main effects plot of the deposition rate.

As can be seen from Table 4 and Figure 1, the deposition rate increased slightly from 24.4 to $27.2 \mathrm{~nm} / \mathrm{min}$ at temperatures ranging from 100 to $180^{\circ} \mathrm{C}$, with a range of 2.8 . For $\mathrm{Ar} / \mathrm{O}_{2}$, the deposition rate of 30:3 was $36.2 \mathrm{~nm} / \mathrm{min}$, which is significantly higher than the $19.6 \mathrm{~nm} / \mathrm{min}$ of $30: 30$ and extremely different to the rate for 16.6; in other words, the deposition rate tends to accelerate with the increase of the $\mathrm{Ar} / \mathrm{O}_{2}$ ratio. When sputtering power increased from 80 to $140 \mathrm{~W}$, the deposition rate increased from 18.6 to $33.4 \mathrm{~nm} / \mathrm{min}$, almost linearity, and the range was 14.8. According to the range analysis table and figures, the most important factor affecting the deposition rate of IGZO thin films at the current parameter levels is the $\mathrm{Ar} / \mathrm{O}_{2}$ ratio, with the largest extreme difference of 16.6, followed by RF sputtering power and temperature. The deposition rate of IGZO film proposed was the fastest at $46.8 \mathrm{~nm} / \mathrm{min}$ under $\mathrm{C} 7$ parameters.

The effects of sputtering parameters on the deposition rate can be explained as follows. At a high $\mathrm{Ar} / \mathrm{O}_{2}$ ratio, enough $\mathrm{Ar}$ ions can reach the target surface and bombard target atoms. At this point, the sputtering atoms are less subject to secondary collisions and scattering, and can successfully fall on the substrate. As the ratio of $\mathrm{O}_{2}$ increases, the probability of sputtering atoms colliding and scattering increases, and the film deposition rate decreases. With the increase of sputtering power, the Ar ions get higher energy, and the more bombardment of the target, the higher the number of sputtered atoms, thereby increasing the deposition rate. The higher the temperature, the faster the rate of atomic thermal motion, and the quicker the sputtering atoms reach the base. However, it can be seen that temperature had little influence on the deposition rate of the films. This may have been due to the fact that temperature variations were small.

\subsection{The Fabrication of a Crystalline IGZO Film}

The sputtering time of $\mathrm{C} 1-\mathrm{C} 9$ was controlled by using the deposition rate results of Section 3.1 to obtain thin film samples with a thickness of $200 \mathrm{~nm}$, labeled S1-1 to S9-1. The crystallographic quality of the samples was analyzed by XRD. 
Figure 2 compares $2 \theta$ XRD spectra of IGZO films. The XRD images showed that all samples had a small hilly projection at about $25^{\circ}$, which is the diffraction peak of the glass substrate. With temperatures below $140{ }^{\circ} \mathrm{C}$ and an $\mathrm{Ar} / \mathrm{O}_{2}$ ratio of 30:3, no samples showed crystallographic characteristics and the films prepared were a-IGZO. The S9-1 sample showed a significant diffraction peak around $31^{\circ}$; the S6- 1 and S8- 1 samples had a weak diffraction peak there, indicating crystal IGZO films were formed the S9-1 conditions [12]. According to the standard PDF database (PDF number 38-1104), the peak is derived from a (009) plane of crystal IGZO, indicating that IGZO film prepared by C9 had good c-axial crystallinity. Additionally, the interplanar spacing of S9-1 calculated from the XRD map is $0.292 \mathrm{~nm}$.

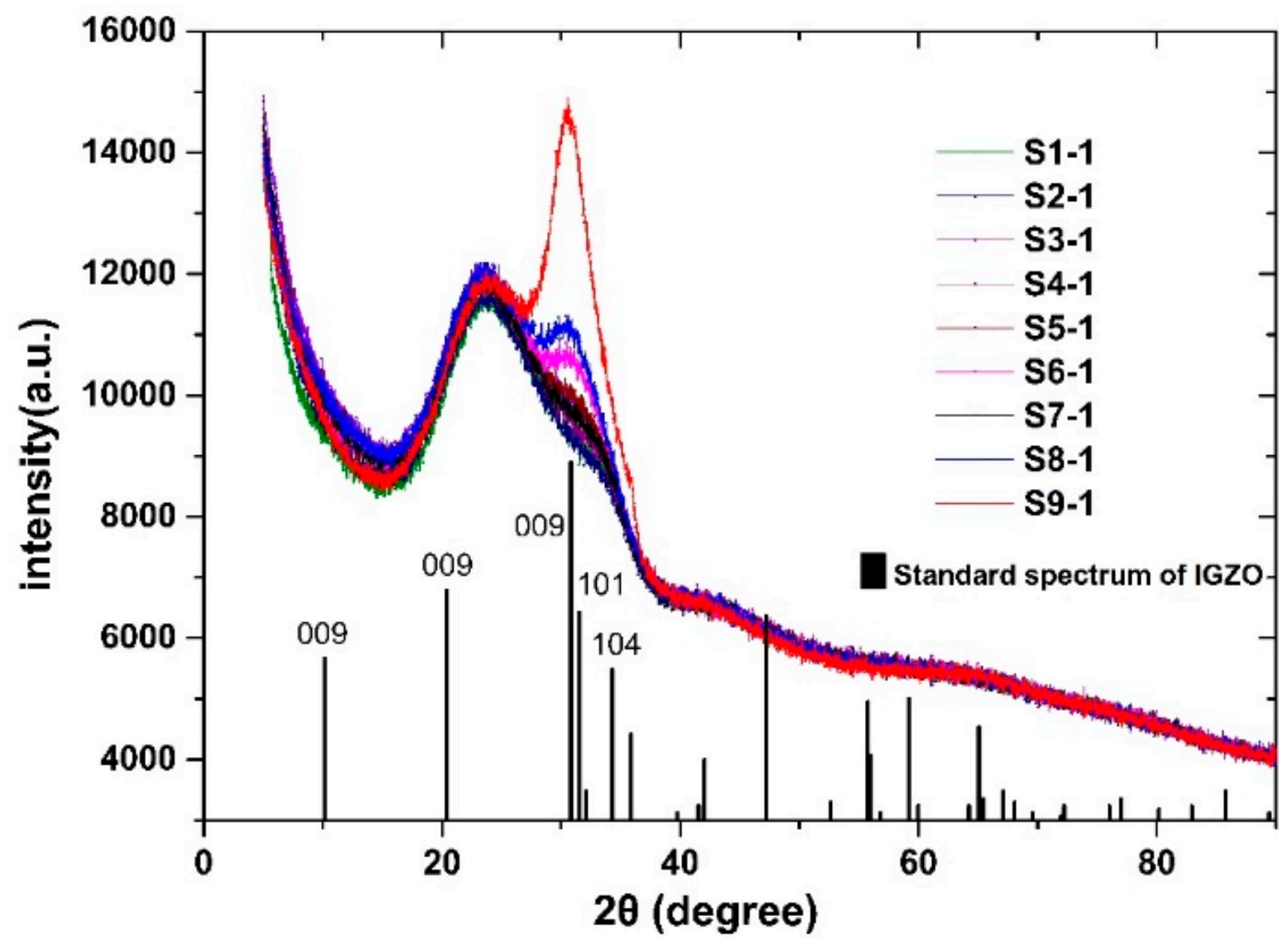

Figure 2. XRD spectrum of prepared IGZO thin films and the standard spectrum diagram of IGZO.

We further characterized the S9-1 thin films by HRTEM imaging. Figure 3 shows an HRTEM image of S9-1 powder on a copper wire screen, showing a clear crystal structure in the middle region. We used a Fast Fourier Transform (FFT) diffractogram (inset of Figure 3) of the HRTEM image to quantify the crystal structure of the prepared IGZO thin film and the expected hexagonal pattern appeared, indicating the IGZO thin film with a structure of c-axis aligned crystal. 


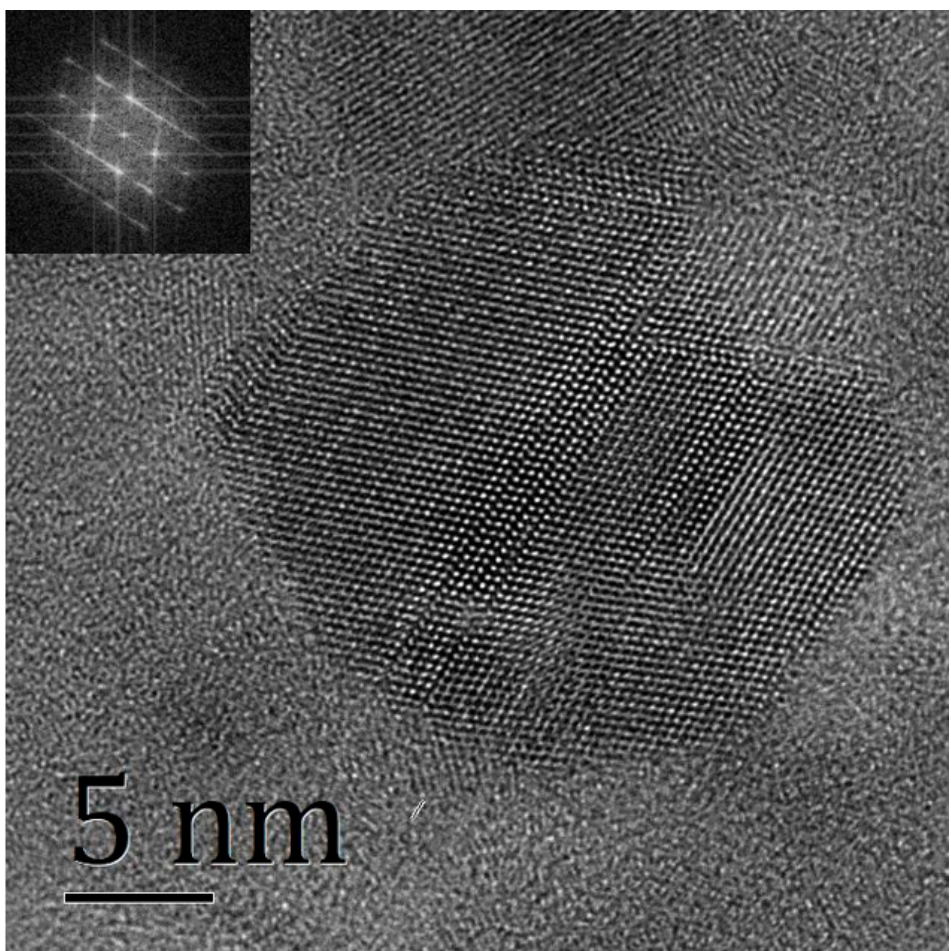

Figure 3. HRTEM image and FFT diffractogram (inset) of S9-1.

Moreover, we calibrated the grain orientation of the crystal IGZO by comparing the FFT diffractogram with the standard PDF card (PDF number 38-1104) and verified the 009 grain face, as shown in the Figure 4. The grain orientation was applied back to the HRTEM diagram for calculation of grain spacing. In accordance with the direction of the calibration in Figure $4 a$, we measured the grain surface distance of five layers on the HRTEM image. The measured value was $1.449 \mathrm{~nm}$ and the final interplanar spacing was $0.290 \mathrm{~nm}$, which is basically consistent with the result calculated by using XRD map in Section 3.1.

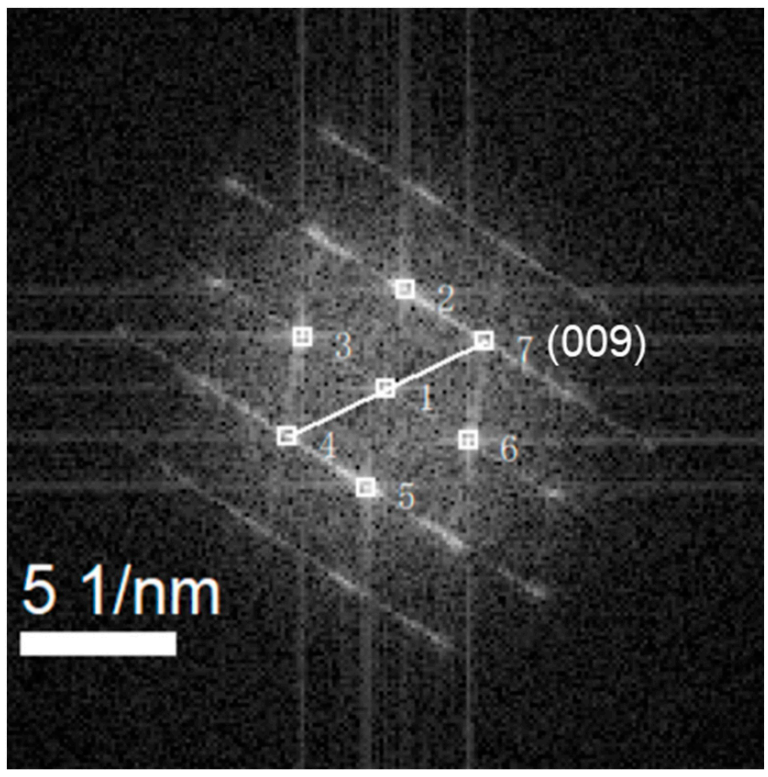

(a)

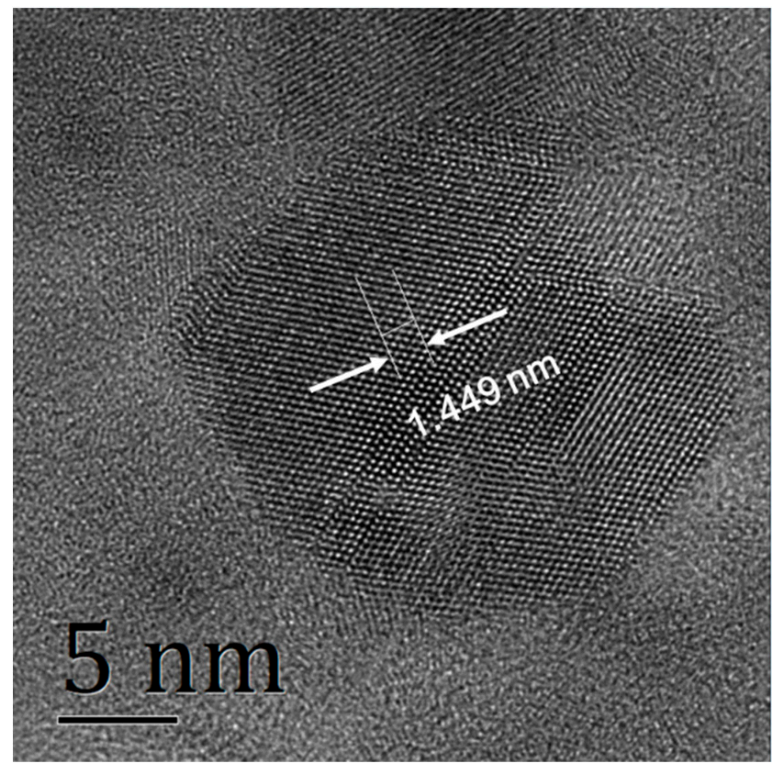

(b)

Figure 4. The interplanar spacing was obtained from the HRTEM image: (a) calibrated crystallographic orientation on an FFT diffractogram and (b) the corresponding interplanar spacing on an HRTEM image of five layers. 
Based on the above analysis, we determined that crystallized IGZO films were generated by using C9. Comparison with other conditions, especially $\mathrm{C} 6$ and $\mathrm{C} 8$, led to the conclusion that the most important parameters affecting the crystallization state are temperature and $\mathrm{O}_{2}$ ratio.

Many other oxide materials, such as $\mathrm{ZnO}$, are known to form crystalline films at high temperatures $[18,19]$. The growth mechanism of sputtering crystal oxides includes nucleation on an initial disordered (about $5 \mathrm{~nm}$ ) layer; subsequent ordered growth occurs if the substrate temperature is high enough to cause coalescence $[20,21]$. We believe that the crystallized IGZO film forms through a similar nucleation process in the early stages of deposition. At low temperatures, the mobility of the atoms is not enough to form these nuclei, or to grow laterally at a rate sufficient in order to coalesce into a coherent membrane. Above $140{ }^{\circ} \mathrm{C}$, the films begin to grow more and more in an orderly fashion. The effect of the $\mathrm{O}_{2}$ ratio on the crystalline state is more pronounced at the stage of membrane growth. When the oxygen ratio is high, it is easier to form a complete crystal structure, and the probability of forming a disordered structure with more oxygen vacancy is reduced. While it is clear that nucleation of grains seems much easier with high $\mathrm{O}_{2}$ content, the direct connection between oxygen re-sputtering and alignment remains unclear.

\subsection{The Corrosion Resistance of the Crystallized IGZO Film}

The crystallized IGZO film was expected to have better stability, and we compared its acid corrosion resistance with a-IGZO. IGZO thin film samples with $300 \mathrm{~nm}$ thickness were prepared on the glass substrate by using C1 and C9 from Table 3, labeled S1-2 (a-IGZO sample) and S9-2 (crystal IGZO sample) respectively. S1-2 and S9-2 were then coated with photoresists, and we exposed half of them after lithography development, and then they were placed in a dilute hydrochloric acid solution ( $\mathrm{HCL}: \mathrm{H}_{2} \mathrm{O}=1: 10$ by volume) for 40 seconds each. Figure 5 shows the cross-sectional scanning electron microscope (SEM) diagrams of S1-2 and S9-2 after etching. According to the differential between the thickness of the unetched IGZO film under the protection of a photoresist and that of the unprotected film, the etching rate of two samples can be calculated.

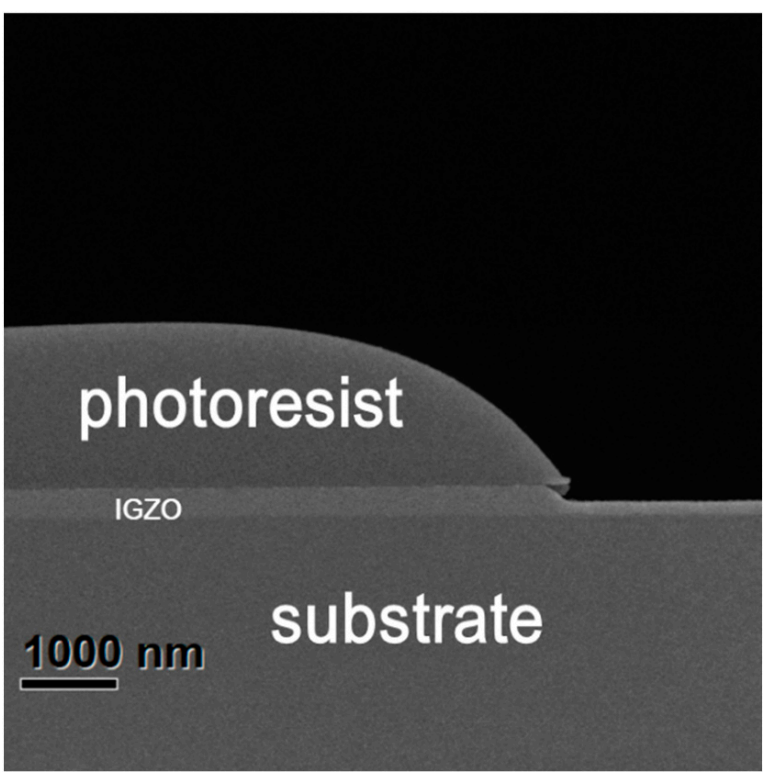

(a)

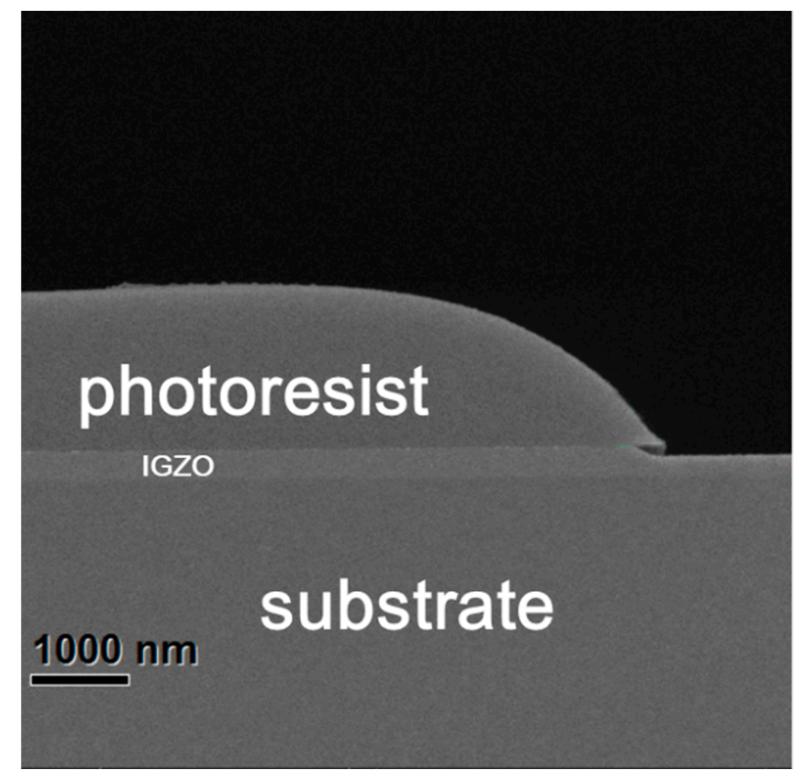

(b)

Figure 5. The cross-sectional SEM images of (a) S1-2 (a-IGZO film) and (b) S9-2 (crystallized IGZO film) after etching. 
As can be seen from Figure 5, the etching depth of S1-2 was significantly greater than that of the S9-2, which means that a-IGZO thin film was more susceptible to acid corrosion than the proposed crystal IGZO film. We measured the height differences at the steps in Figure $5 \mathrm{a}, \mathrm{b}$ to be 174.7 and $100.7 \mathrm{~nm}$ respectively. By dividing by time $40 \mathrm{~s}$, we got the etching rates of 4.35 and $2.50 \mathrm{~nm} / \mathrm{s}$. This means that the corrosion resistance of the prepared crystalline IGZO is $74 \%$ higher than that of a-IGZO. The improvement may be due to a more compact structure of the crystalline IGZO.

\section{Conclusions}

In conclusion, we report the deposition of a crystallized IGZO thin film by RF sputtering. The effects of temperature, $\mathrm{Ar} / \mathrm{O}_{2}$ ratio and power on film formation during $\mathrm{RF}$ sputtering were analyzed via DOE method. The experiment results show that only a-IGZO films can be obtained at low temperatures or for low $\mathrm{O}_{2}$ ratios. At $140{ }^{\circ} \mathrm{C}$ with a $33 \% \mathrm{O}_{2}$ fraction, crystal formation begins and increases with increasing temperature and $\mathrm{O}_{2}$ ratio. At the current conditions, IGZO thin films with the best crystallization performance were obtained at $180{ }^{\circ} \mathrm{C}, \mathrm{O}_{2}$ ratio $50 \%$ and power $110 \mathrm{~W}$.

XRD images were used to characterize the structures of IGZO films. Film deposition under optimized conditions shows a significant diffraction peak around $31^{\circ}$, and the peak is derived from a (009) plane of crystal IGZO, indicating that the film has good crystallinity. The interplanar spacing calculated from XRD map was $0.292 \mathrm{~nm}$. The crystallized film was further characterized by HRTEM. An HRTEM image and FFT diffractogram show that the prepared film had a clear crystal structure, and the interplanar spacing measured from the HRTEM image was $0.290 \mathrm{~nm}$, which is basically consistent with the results calculated by using XRD.

The corrosion resistance of the prepared crystallized IGZO thin film was characterized by the etching rate. The experimental results show that the acid corrosion resistance of crystalline IGZO films can be increased by $74 \%$, which indicates that this film can provide more stable performance in applications such as BCE TFTs.

The future work will focus on expanding sputtering parameters around C9 conditions, exploring the influences of sputtering parameters on the crystallinity of thin films and applying the prepared crystalline films to TFT devices to explore their effects on electrical properties.

Author Contributions: Conceptualization, X.W. and S.W.; data curation, X.W., Z.S. and J.L.; formal analysis, X.W.; funding acquisition, X.W.; investigation, X.W. and Z.S.; methodology, X.W. and S.W.; project administration, X.W.; resources, S.W.; software, X.W. and J.L.; supervision, X.W. and S.W.; validation, X.W., Z.S., J.L. and S.W.; visualization, X.W. and Z.S.; writing-original draft preparation, X.W.; writing - review and editing, X.W., Z.S. and J.L. All authors have read and agreed to the published version of the manuscript.

Funding: This research was funded by the National Natural Science Foundation of China (grant numbers 62004120 and 62004108) and the Scientific Research Startup Foundation of Shaanxi University of Science and Technology (grant number 2018BJ-57). The APC was funded by Scientific Research Startup Foundation of Shaanxi University of Science and Technology (grant number 2018BJ-57).

Institutional Review Board Statement: Not applicable.

Informed Consent Statement: Not applicable.

Data Availability Statement: All data generated or analyzed during this study are included in this published article.

Acknowledgments: The authors would like to thank Yang Bin for the help with the experiment.

Conflicts of Interest: The authors declare no conflict of interest. 


\section{References}

1. Wang, R.Z.; Wu, S.L.; Li, X.Y.; Zhang, J.T. The electrical performance and gate bias stability of an amorphous InGaZnO thin-film transistor with $\mathrm{HfO}_{2}$ high-k dielectrics. Solid State Elecrton. 2017, 133, 6-9. [CrossRef]

2. Li, D.Q.; Nan, H.Y.; Mou, P.L.; Xu, C.Y.; Shao, F.; Gu, X.F.; Ostrikov, K.; Xiao, S.Q. High performance IGZO-based phototransistors by BN/BP interface engineering. Nanotechnology 2021, 32, 025201. [CrossRef] [PubMed]

3. Kim, K.; Park, J.W.; Lee, D.; Cho, Y.H.; Kim, Y.S. Precise Turn-On Voltage Control of MIOSM Thin-Film Diodes with Amorphous Indium-Gallium-Zinc Oxide. ACS Appl. Mater. Interfaces 2021. [CrossRef] [PubMed]

4. Lee, J.; Kim, M.J.; Yang, H.; Kim, S.; Yeom, S.; Ryu, G.; Shin, Y.; Sul, O.; Jeong, J.K.; Lee, S.-B.; et al. Extended-Gate Amorphous InGaZnO Thin Film Transistor for Biochemical Sensing. IEEE Sens. J. 2021, 21, 178-184. [CrossRef]

5. Hong, E.K.; Cho, W.J. High sensitivity In-Ga-Zn-O nanofiber-based double gate field effect transistors for chemical sensing. Sens. Actuat. B-Chem. 2021, 326, 128827. [CrossRef]

6. Uenuma, M.; Umeda, K.; Felizco, J.; Senaha, D.; Uraoka, Y. Flexible TEG Using Amorphous InGaZnO Thin Film. J. Electron. Mater. 2019, 48, 1971-1975. [CrossRef]

7. Huang, Y.A.; Peng, K.P.; Meng, Y.C. A novel photoresist-based film-profile engineering scheme for fabricating double-gated, recess-channel IGZO thin-film transistors. Jpn. J. Appl. Phys. 2020, 59, SGGJ01. [CrossRef]

8. Nomura, K.; Ohta, H.; Takagi, A.; Kamiya, T.; Hirano, M.; Hosono, H. Room-temperature fabrication of transparent flexible thin-film transistors using amorphous oxide semiconductors. Nature 2004, 432, 488. [CrossRef] [PubMed]

9. Chiang, H.Q.; Wager, J.F.; Hoffman, R.L.; Jeong, J.; Keszler, D.A. High Mobility Transparent Thin-Film Transistors with Amorphous Zinc tin Oxide Channel Layer. Appl. Phys. Lett. 2005, 86, 013503. [CrossRef]

10. Ge, S.M.; Li, S.; Chen, S.J.; Kong, X.-Y.; Meng, Y.-H.; Shi, W.; Shi, L.Q.; Wu, W.; Liu, X.; Gan, Q.-M.; et al. Development of Cu BCE-Structure IGZO TFT for a High-ppi 31-in. 8K $\times 4 \mathrm{~K}$ GOA LCD. In SID Symposium Digest of Technical Papers; Blackwell Publishing Ltd.: Oxford, UK, 2017; pp. 592-595.

11. Watanabe, K.; Iwaki, Y.; Uchida, Y.; Nakamura, D.; Ikeda, H.; Miyake, H.; Hirakata, Y.; Yamazaki, S.; Katayama, M.; Cho, T. 18.3 An 8.67-in Foldable OLED Display with an In-cell Touch Sensor. In SID Symposium Digest of Technical Papers; Blackwell Publishing Ltd.: Oxford, UK, 2015; pp. 246-249.

12. Yamazaki, S.; Hirohashi, T.; Takahashi, M.; Adachi, S.; Tsubuku, M.; Koezuka, J.; Okazaki, K.; Kanzaki, Y.; Matsukizono, H.; Kaneko, S.; et al. Back-channel-etched thin-film transistor using c-axis-aligned crystal In-Ga-Zn oxide. J. SID 2014, $22,55-67$. [CrossRef]

13. Yamazaki, S.; Koyama, J.; Yamamoto, Y.; Okamoto, K. Research, development, and application of crystalline oxide semiconductor. In SID Symposium Digest of Technical Papers; Blackwell Publishing Ltd.: Oxford, UK, 2012; Volume 43, pp. $183-186$.

14. Park, K.; Park, H.W.; Shin, H.S.; Bae, J.; Park, K.-S.; Kang, I.; Chung, K.-B.; Kwon, J.-Y. Reliability of Crystalline Indium-GalliumZinc-Oxide Thin-Film Transistors under Bias Stress with Light Illumination. IEEE Trans. Electron Devices 2015, 62, $2900-2905$. [CrossRef]

15. Hiramatsu, T.; Nakashima, M.; Kikuchi, E.; Ishihara, N.; Tsubuku, M.; Dairiki, K.; Yamazaki, S. Correlation between crystallinity and oxygen vacancy formation in In-Ga-Zn oxide. Jpn. J. Appl. Phys. 2016, 55, 21203. [CrossRef]

16. Lynch, D.M.; Zhu, B.; Barnaby, D.A.; Muller, D.A.; Ast, D.G.; Greene, R.G.; Thompson, M.O. Characterization of reactively sputtered c-axis aligned nanocrystalline InGaZnO4. Appl. Phys. Lett. 2014, 105, 262103. [CrossRef]

17. Yamazaki, S. Crystalline Oxide Semiconductor Using CAAC-IGZO and its Application. ECS Trans. 2014, 64, 155-164. [CrossRef]

18. Sharma, P.; Sreenivas, K.; Belova, L.M.; Rao, K.V. Imaging of piezoelectric activity in laser-ablated c-axis-oriented LiNbO $3 / \mathrm{ZnO}$ thin film multilayer on glass using atomic force microscopy. J. Mater. Res. 2003, 18, 2025-2028. [CrossRef]

19. Gupta, V.; Sreenivas, K. Pulsed laser deposition of zinc oxide (ZnO). In Zinc Oxide Bulk, Thin Films and Nanostructures; Jagadish, C., Pearton, S.J., Eds.; Elsevier: Amsterdam, The Netherlands, 2006; pp. 85-174.

20. Van De Pol, F.; Blom, F.; Popma, T. Rf planar magnetron sputtered ZnO films I: Structural properties. Thin Solid Films 1991, 204, 349-364. [CrossRef]

21. Yoshino, Y.; Inoue, K.; Takeuchi, M.; Ohwada, K. Effects of interface micro structure in crystallization of ZnO thin films prepared by radio frequency sputtering. Vacuum 1998, 51, 601-607. [CrossRef] 